\title{
Computed tomographic findings of brain and skull in myotonic dystrophy
}

\author{
ELIESER AVRAHAMI,* AMIRAM KATZ, $\dagger$ NATHAN BORNSTEIN,$\dagger$ \\ AMOS D KORCZYN†
}

From the Departments of Radiology, ${ }^{*}$ and Neurology, $\dagger$ Tel-Aviv Medical Centre, and the Tel-Aviv University Sackler School of Medicine, Tel-Aviv, Israel

SUMMARY Twenty-four patients with myotonic dystrophy underwent computed tomographic examination of the skull and brain. The results were compared with those of 20 normal subjects of similar age and sex distribution. Microcephaly and thickening of the calvarium were frequently observed. Some cases showed basal ganglia calcification. Our findings confirm that cranial hyperostosis and brain pathology is a common manifestation of this systemic disease.

Small sella turcica, overdevelopment of the frontal sinuses, and hyperostosis of the calvarian bones have been reported in patients with myotonic dystrophy. Brain atrophy and hydrocephalus have also been described. ${ }^{1-5}$ However, most of these studies were based on skull radiographs or brain pneumograms. The availability of computed tomography (CT) has enabled us to study the prevalence of changes in the brain and skull in a group of patients with myotonic dystrophy.

\section{Material and methods}

Twenty-four patients ( 12 females) ranging in age from 25 to 59 years, with a diagnosis of myotonic dystrophy, underwent axial CT examination of the skull, brain, and orbits. Twenty patients ( 10 females) in an age range from 24 to 58 years, who underwent brain CT examination which was evaluated as normal, were used as a control group.

The patients were identified in a country-wide survey of myotonic dystrophy in Israel, performed by one of us

Address for reprint requests: Professor AD Korczyn, Tel-Aviv University, Sackler School of Medicine, Ramat Aviv 69978, Israel.

Received 24 April 1986 and in revised form 24 July 1986. Accepted 26 July 1986
(ADK). Those living in the Tel-Aviv area were invited to participate in the present study. No other selection was made.

CT examinations were done using an Elscint 700 Scanner. Non-enhanced axial slices of the skull, including brain- and bone-window cuts, were used. The CT slices were $12 \mathrm{~mm}$ wide each, with increments of $10 \mathrm{~mm}$. Measurement of the frontal, occipital, and temporal bone thickness was performed. We have not studied the parietal bone, since its angulation prevents reliable measurement in the axial cut.

\section{Results}

Patients with myotonic dystrophy showed significant cranial hyperostosis. On the basis of the CT evaluation, the patients clearly separated into two groups. Most $(n=17)$ had hyperostosis, while the others ( $n$ $=7$ ) appeared essentially normal (table 1). Thickening in the first group included all three layers of the bone: external and internal tables as well as diploe. A typical example is shown in fig 1 . Measurements of the orbits, eyeballs, and the bones of the base of skull did not show significant differences between the groups.

Brain slice area was measured with the computer grid, as shown in fig 2. The measurements showed significant microcephaly in myotonic dystrophy

Table 1 Thickness of the calvariae bones in myotonic dystrophy

\begin{tabular}{|c|c|c|c|c|}
\hline & $\begin{array}{l}\text { Control group } \\
(n=20)\end{array}$ & $\begin{array}{l}\text { All patients } \\
(n=24)\end{array}$ & $\begin{array}{l}\text { Patients with calvarian } \\
\text { hyperostosis }(n=17)\end{array}$ & $\begin{array}{l}\text { Patients with normal } \\
\text { skull }(n=7)\end{array}$ \\
\hline $\begin{array}{l}\text { Frontal bone } \\
\text { Temporal bone } \\
\text { Occipital bone }\end{array}$ & $\begin{array}{r}10.5 \pm 1.0 \\
8.9 \pm 1.2 \\
10.6 \pm 1.1\end{array}$ & $\begin{array}{l}15 \cdot 2 \pm 2 \cdot 1^{*} \\
11 \cdot 3 \pm 1 \cdot 8^{*} \\
15 \cdot 2 \pm 2 \cdot 2^{*}\end{array}$ & $\begin{array}{l}16 \cdot 9 \pm 1 \cdot 6^{*} \\
12.4 \pm 1 \cdot 7^{*} \\
18 \cdot 1 \pm 2 \cdot 2^{*}\end{array}$ & $\begin{array}{r}11.1 \pm 1.9 \\
8.6 \pm 1.7 \\
10.9 \pm 2.1\end{array}$ \\
\hline
\end{tabular}

*p < 0.001 , compared with control group (Student's $t$ test). Values are given in mm \pm SD. 

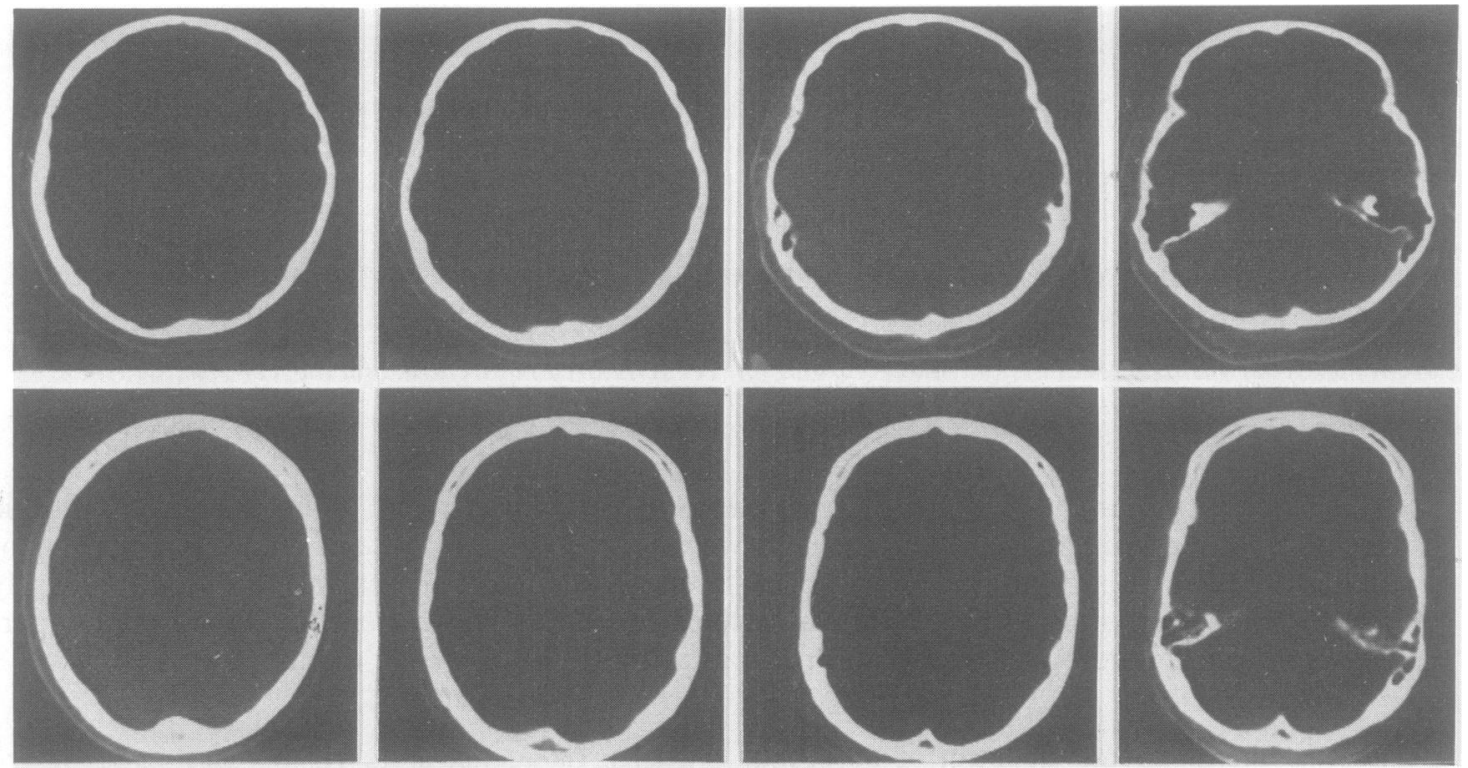

Fig 1 Bony view of a 35 year old male normal subject (upper slices) and a 35 year old male patient with myotonic dystrophy (lower slices).

patients, and this phenomenon was especially marked in the first group. These 17 myotonic dystrophy patients who had calvarian thickening, showed a $15-25 \%$ area reduction at several levels in comparison with the control group (table 2).

Additionally, three linear brain parameters were measured, all of which were also significantly reduced in the first group (table 3): (a) the largest anteroposterior distance from the internal tables of the frontal and occipital bones, (b) the largest transverse distance between the internal tables of both temporal plates, (c) the vertical distance, estimated from the
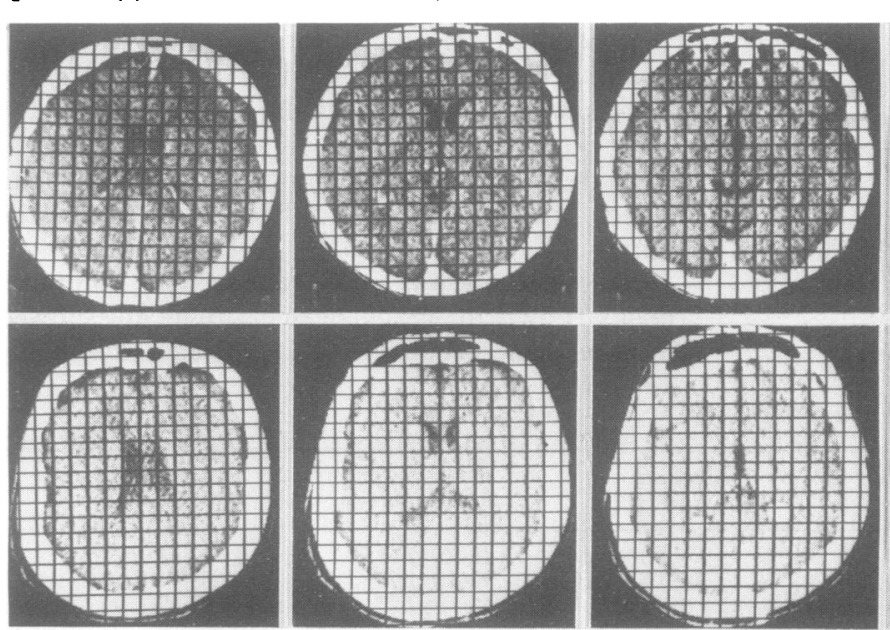
cephaly.
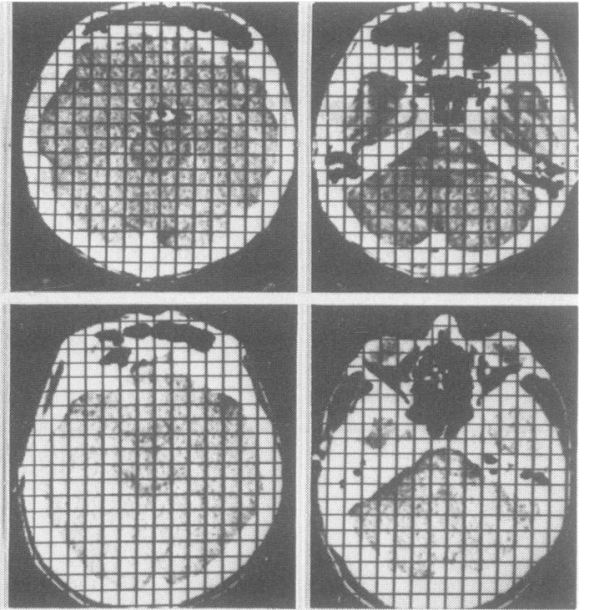

Fig 2 CT scan of a 27 year old male normal subject (upper slices) and a 23 year old male patient with myotonic dystrophy (lower slices). Note the calvarian thickness and reduction of the brain tissue surface in the lower slices. Every quadrant of the grid is $1 \mathrm{~cm}^{2}$.

number of CT slices between the foramen magnum

The reduction of the linear and area parameters of the brain in 17 myotonic dystrophy patients waso three-dimensional, and was consistent with micro $\overrightarrow{0}$ patients or the duration of the disease on one hand, and the degree of hyperostosis or brain atrophy on the other. The myotonic dystrophy patients under the age of 40 years ( 15 patients) with a shorter duration of the disease, had almost the same average skull and 
Table 2 Area of brain slices in myotonic dystrophy

\begin{tabular}{|c|c|c|c|c|}
\hline Level of slice & $\begin{array}{l}\text { Control group } \\
(n=20)\end{array}$ & $\begin{array}{l}\text { All patients } \\
(n=24)\end{array}$ & $\begin{array}{l}\text { Patients with calvarian } \\
\text { hyperostosis }(n=17)\end{array}$ & $\begin{array}{l}\text { Patients with normal } \\
\text { skull }(n=7)\end{array}$ \\
\hline $\begin{array}{l}\text { Posterior fossa } \\
\text { Quadrigeminal cistern, lower part of }\end{array}$ & $48 \cdot 1 \pm 4 \cdot 9$ & $45 \cdot 3 \pm 7 \cdot 0$ & $40 \cdot 7 \pm 6 \cdot 2^{*}$ & $48 \cdot 4 \pm 5 \cdot 1$ \\
\hline $\begin{array}{l}\text { 3rd ventricle } \\
\text { Upper part of } 3 \text { rd ventricle } \\
10 \mathrm{~mm} \text { above } 3 \text { rd ventricle }\end{array}$ & $\begin{array}{l}162.4 \pm 5.8 \\
164.9 \pm 6.7 \\
166.8 \pm 6 \cdot 1\end{array}$ & $\begin{array}{l}138.5 \pm 7 \cdot 3^{*} \\
137.9 \pm 12 \cdot 8^{*} \\
141 \cdot 1 \pm 9 \cdot 7^{*}\end{array}$ & $\begin{array}{l}126 \cdot 3 \pm 6 \cdot 8^{*} \\
127 \cdot 9 \pm 8 \cdot 4^{*} \\
125 \cdot 4 \pm 7 \cdot 4^{*}\end{array}$ & $\begin{array}{l}161 \cdot 8 \pm 6 \cdot 2 \\
163.8 \pm 6 \cdot 6 \\
168 \cdot 3 \pm 7 \cdot 1\end{array}$ \\
\hline
\end{tabular}

${ }^{*} \mathrm{p}<0.001$, compared with control group (Student's $t$ test). Values are given in $\mathrm{cm}^{2}$.

Table 3 Parameters of brain size in myotonic dystrophy

\begin{tabular}{|c|c|c|c|c|}
\hline Level of slice & $\begin{array}{l}\text { Control group } \\
(n=20)\end{array}$ & $\begin{array}{l}\text { All patients } \\
(n=24)\end{array}$ & $\begin{array}{l}\text { Patients with calvarian } \\
\text { hyperostosis }(n=17)\end{array}$ & $\begin{array}{l}\text { Patients with normal } \\
\text { skull }(n=7)\end{array}$ \\
\hline \multirow{6}{*}{$\begin{array}{l}\text { Maximum antero-posterior inner } \\
\text { diameter of the skull (mm) } \\
\text { Maximum transverse inner diameter of } \\
\text { the skull (mm) (A) } \\
\text { Number of slices (10 mm each) } \\
\text { Maximum distance of sellae media } \\
\text { separated only by septum } \\
\text { pellucidum (mm) (B) } \\
\text { Maximum distance between tips of } \\
\text { anterior horns (mm)(C) } \\
\text { Maximum width of 3rd ventricle (mm) } \\
\text { Maximum width of interhemispheric } \\
\text { fissure (mm) } \\
\text { Cella media index (A/B) } \\
\text { Anterior horn index (A/C) } \\
\text { Average of the four widest peripheral } \\
\text { sulci (mm) }\end{array}$} & $163 \cdot 2 \pm 4 \cdot 3$ & $152 \cdot 3 \pm 8 \cdot 5^{*}$ & $141 \cdot 5 \pm 5 \cdot 2^{*}$ & $161 \cdot 4 \pm 7 \cdot 2$ \\
\hline & $\begin{array}{l}91 \cdot 2 \pm 5 \cdot 1 \\
12 \cdot 5 \pm 1 \cdot 1\end{array}$ & $\begin{array}{l}87.9 \pm 9.2 \\
11 \cdot 3 \pm 1.0^{*}\end{array}$ & $\begin{array}{r}80.2 \pm 7 \cdot 1 \\
9.9 \pm 0.6^{*}\end{array}$ & $\begin{array}{l}93 \cdot 8 \pm 6.1 \\
12.9 \pm 0.9\end{array}$ \\
\hline & $18 \cdot 2 \pm 0.7$ & $18 \cdot 8 \pm 1 \cdot 5$ & $19 \cdot 3 \pm 1 \cdot 2$ & $17 \cdot 3 \pm 0 \cdot 8^{* *}$ \\
\hline & $\begin{array}{r}26.1 \pm 1.0 \\
3.9 \pm 0.4\end{array}$ & $\begin{aligned} & 29.9 \pm 2.9 \\
& 4 \cdot 1 \pm 1.5^{* *}\end{aligned}$ & $\begin{aligned} & 31 \cdot 2 \pm 1 \cdot 6^{*} \\
& 4 \cdot 4 \pm 1 \cdot 1^{*}\end{aligned}$ & $\begin{array}{c}27.3 \pm 2.0^{* *} \\
3.8 \pm 0.6\end{array}$ \\
\hline & $\begin{array}{l}1.1 \pm 0.3 \\
5.0 \pm 1.4 \\
3.5 \pm 1.5\end{array}$ & $\begin{array}{l}1.6 \pm 0.8^{*} \\
4.7 \pm 1.5 \\
3.1 \pm 1.5\end{array}$ & $\begin{array}{l}1.9 \pm 0.6^{*} \\
4.2 \pm 0.9 \\
2.6 \pm 1.6^{* *}\end{array}$ & $\begin{array}{l}1.0 \pm 0.5 \\
5.4 \pm 1.8 \\
3.3 \pm 1.9\end{array}$ \\
\hline & $1.2 \pm 0.2$ & $1.4 \pm 0.4^{*}$ & $1.8 \pm 0.4^{*}$ & $1 \cdot 1 \pm 0.3$ \\
\hline
\end{tabular}

${ }^{*} \mathrm{p}<0.001,{ }^{* *} \mathrm{p}<0.05$ compared with control group (Student's $t$ test)

brain parameters as the nine patients over 40 years of age, with a longer duration of illness.

Basal ganglia calcification was observed in three female patients with myotonic dystrophy. One of these patients, 33 years old, belonged to the hyperostosis group, and two patients, aged 39 and 42 years respectively, belonged to the normal group. The calcification was bilateral and symmetric, as demonstrated in fig 3 .

In three patients (one female), all with marked calvarian hyperostosis, diffuse brain atrophy was observed, which included symmetrically enlarged lateral and third ventricles, and widened sulci (fig 4)

In order to evaluate a possible relationship between clinical manifestations and the CT findings, patients were separated into those having no limitation in physical activity, or only mild difficulties (mild disability, 16 cases) as opposed to those needing assistance in climbing stairs (severe disability, 8 cases). This evaluation was done by an observer unaware of the CT findings. Among the seven myotonic dystrophy cases who had normal CT findings, only one patient was graded as being severely disabled, while among the 17 patients with hyperostosis, seven were thus graded. This difference is highly significant statistically $\left(\chi^{2}\right.$ test, $\left.\mathrm{p}<0.01\right)$.

\section{Discussion}

Hyperostosis of the calvarium is not a specific phe- nomenon, and can be seen as a normal variant, and in several pathological conditions such as acromegaly, cretinism, osteopetrosis and cerebral atrophy. The hyperostosis in myotonic dystrophy includes the frontal and occipital bones and, to a similar degree, also the temporal bones, and was thus unlike hyperostosis

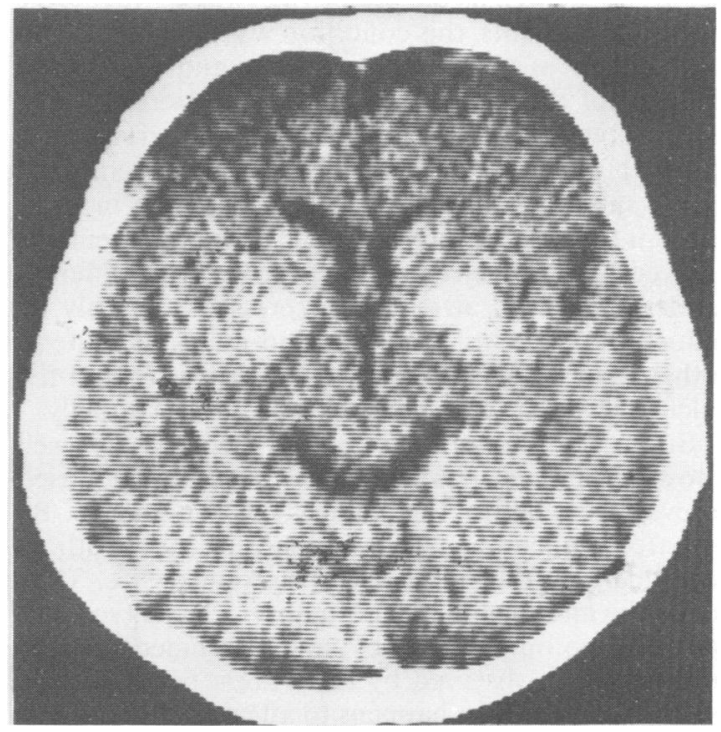

Fig 3 Globus pallidum calcification in a 41 year old female patient with myotonic dystrophy. 

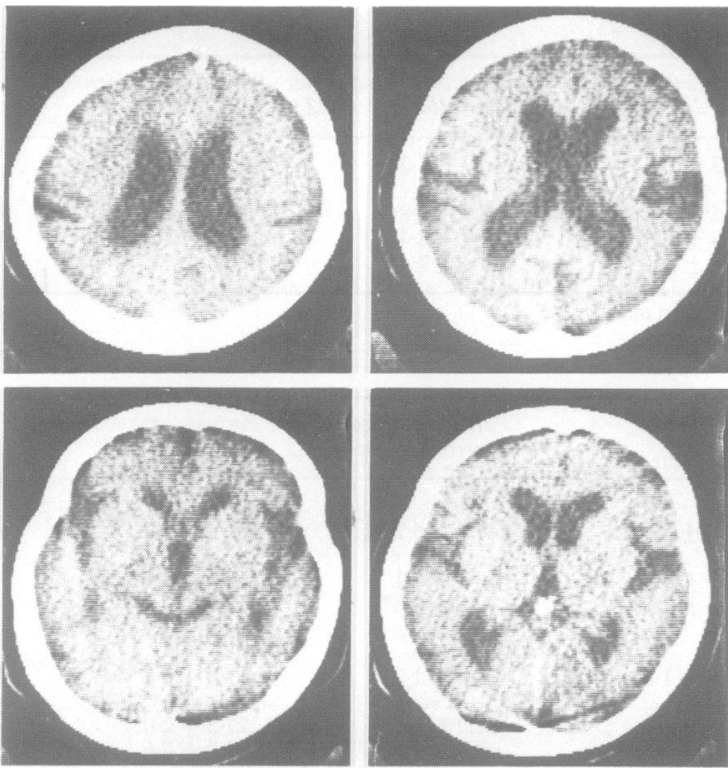

Fig 4 Obvious brain atrophy in a 25 year old male patient with myotonic dystrophy. Note enlarged lateral and third ventricles, ambient cistern, Sylvian fissure and sulci.

frontalis interna. Bones in the base of the skull and other parts of the body seemed not be be involved (unreported data).

Previous studies documenting calvarian hyperostosis in myotonic dystrophy using conventional radiography ${ }^{1-5}$ have not delineated the exact site of involvement. Using CT, we have been able to show that the hyperostosis included the external and internal tables, as well as the diploe (fig 1). In 17 myotonic dystrophy patients, this condition was associated with a reduction of the antero-posterior and bitemporal distance of the brain, associated with decreased distance between foramen magnum and the vertex (fig 1 , tables 1 and 2). The linear parameters mentioned above showed a $12-20 \%$ average reduction in comparison to the control group. The area measurements showed an average reduction of $15-17 \%$ at different levels. This brain atrophy is expressed primarily by reduction of the brain volume and the skull content, rather than by enlargement of the ventricles and the sulci. These changes therefore reflect microcephaly.

Brain changes in myotonic dystrophy are well known from previous studies. ${ }^{67}$ Refsum et al ${ }^{7}$ tried to evaluate whether the changes are progressive. By repeated pneumoencephalography, the authors recorded a further increase in ventricular size. They noted the mild mental subnormality, which is so common in myotonic dystrophy, and concluded that the brain changes observed by them are a manifestation of the disease, which happens to affect several organs. This view is now widely accepted.
It thus seems that in myotonic dystrophy obvious brain changes are relatively common, as judged by CT scans. These changes are more likely to occur in patients with advanced clinical manifestations of weakness, suggesting a more aggressive form of the disease.

Basal ganglia calcification may be seen as an incidental finding in normal people. However, they occurred at a relatively young age in our patients. The coexistence of bony changes may suggest an underlying abnormality of calcium metabolism. Although serum calcium, phosphate, and akaline phosphatase were normal in these patients, a more discrete impairment of calcium metabolism may occur in myotonic dystrophy and its investigation is planned. The myotonic dystrophy patients in our first group had both microcephaly and calvarian hyperostosis. The remaining seven patients, with normal CT had brain and skull parameters similar to those of normal subjects. Because all 17 myotonic dystrophy patients who had microcephaly also had hyperostosis of the calvarian bones, it is possible that the relatively small size of the brain is responsible for the hyperostosis because less pressure is exerted on the bone. This explanation is consistent with the fact that the bones of the base of the skull are not hyperostotic. The unique facial appearance in myotonic dystrophy, reflected by characteristic changes in the facial bones, ${ }^{8}$ may similarly result from a weakened pull by masticatory muscles. However, other explanations may also be considered.

\section{References}

1 Caughey JE. Radiological changes in skull in dystrophia myotonia. $\mathrm{Br}$ J Med 1952;1:137-9.

2 Di Chiro G, Caughey E. Skull changes in eighteen cases of dystrophia myotonica. Acta Radiol (Diagr) (Stockholm) 1960;54:22-8.

3 Gleeson JA, Swann JC, Hughes DTD, Lee FJ. Dystrophia myotonica-a radiological survey. $\mathrm{Br} J$ Radiology 1967;40:96-100.

4 Krain S, Rabinowitz JG. The radiologic features of myotonic dystrophy with presentation of a new finding. Clin Radiol 1971;22:462-5.

5 Lee KF, Lin SR, Hodes PY. New roentgenolgic findings in myotonic dystrophy. An analysis of 18 patients. Am J Roentgenol 1972;115:179-85.

6 Heidrich K, Hagemann P. Hydrocephalus internus et externus in dystrophia myotonica. Psychiat Neurol Psychol (Leipzig) 1958;10:15-21.

Dystrophia myotonia. Repeated pneumoencephalographic studies in ten patients. Neurology 1967;17:345-8.

8 Gazit E, Bornstein NB, Lieberman A, et al. The stomatognathic system in myotonic dystrophy. Eur $J$ Orthodont (in press). 